\title{
A lavoura do algodão no sul dos Estados Unidos antes da Guerra Civil: uma história de amor global entre capitalismo e escravidão
}

Cotton Plantation in the Deep South before the Civil War: A Global Love Affair between Capitalism and Slavery

Antonio Luigi Negro ${ }^{*}, * *$

BAPTIST, Edward. A metade que nunca foi contada: a escravidão e a construção do capitalismo norte-americano. Rio de Janeiro: Paz \& Terra, 2019. 552 p.

Enfim traduzido, o livro de Edward Baptist vem para estimular o conhecimento do passado e a compreensão do mundo contemporâneo. $\mathrm{O}$ autor propõe trazer a lume a metade da História nunca contada: a escravidão estadunidense fazendo par com o capitalismo industrial britânico, e, também, o seu papel na formação do capitalismo estadunidense, de 1790 a 1860. Debruçada sobre essa aliança entre lavoura escravista e Revolução Industrial no Atlântico Norte, a obra também faz ver a experiência de homens e mulheres escravizados, africanos ou afrodescendentes. Com cenas vívidas, ampla e minuciosa pesquisa, reconstitui a experiência e a ação - agency - dos trabalhadores. O livro de Baptist comprova, novamente, o "impacto dos em tese impotentes sobre os poderosos em termos econômicos e políticos" (Greenidge, 2020).

O autor Edward Baptist é professor da Universidade de Cornell e historiador dos Estados Unidos, tendo o século XIX como recorte cronológico. Estuda a vida de homens e mulheres escravizados no Sul, região que é cenário de uma maciça expansão da escravatura, devido à lucratividade do algodão (o que terminou por precipitar a Guerra Civil em 1861). O público a que o livro se destina é aquele que deseja conhecer melhor a força da escravidão, por um lado, e, por outro, também a força dos escravizados. Também mata a sede de quem quer entender o contemporâneo apego dos estadunidenses ao lado perdedor da guerra, o sulista, que quis se separar do país para fundar um outro, a fim de manter a escravidão. Os efeitos duradouros desse apego podem ser

\footnotetext{
* Universidade Federal da Bahia (UFBA), Salvador, BA, Brasil. negro@ufba.br <https://orcid.org/00000001-7253-355X>

** Pesquisador CNPq.
} 
simbolizados hoje, mais do que nunca, nas imagens da tentativa de golpe de Estado em 6 de janeiro de 2021, a qual, embora um fiasco, conseguiu desfraldar a bandeira confederada dentro do Capitólio.

A metade que nunca foi contada mostra ser preciso conhecer a História da lavoura, um cenário de saques e assaltos a seres humanos frágeis e indefesos, composto de mortes, tortura e das mais diversas perversidades, a começar pelo estupro das mulheres. A escravidão, esclarece Baptist, foi um crime intencional, resultante da visível deliberação de se fazer dinheiro. É o que diz o ex-escravizado Grand: "se você quer controlar uma pessoa, roube a pessoa. Roube-a de seu povo". Depois, "leve-a a um lugar onde você possa roubar tudo mais dela: seu futuro, sua criatividade, seu ventre" (Baptist, 2019, p. 253). Essa é a "verdadeira razão" por trás da História do século XIX, explicando a escravidão como um fenômeno cuja característica básica foi a expansão permanente. Para que o roubo citado por Grand não fosse visto como um crime, foi forjada a trapaça da supremacia racial branca. E isto faz perceber a atualidade do livro, que ajuda a entender tanta agressividade na defesa de uma trapaça que legitima um crime...

Esta resenha se detém naquilo que é a grande contribuição da obra: a de ter colocado no centro da análise o exame da expansão - econômica, territorial e demográfica - da escravidão. Para entender isso, é preciso perceber a força da escravidão. O primeiro ponto crucial de Baptist é contra o errôneo ou mal-intencionado cálculo que estima um término para a escravidão. Previsão baseada no fim do tráfico e no gradualismo de leis abolicionistas, sugere irrefreável tendência da "civilização ocidental" no rumo do seu aperfeiçoamento contínuo, promovendo a (inexistente) transição da escravidão à liberdade. Porém, de fato, no lugar de um fenômeno declinante - tendente a zero -, Baptist demonstra que a escravidão é um sistema altamente lucrativo, geograficamente móvel, com frentes e fronteiras renováveis e dinâmicas. No lugar de um condenado contando os dias do seu fim, o escravismo se expandiu territorialmente e demograficamente (apesar do fim do tráfico). Teve, então, de lidar com a pressão contrária de homens e mulheres escravizados, desejosos de relações familiares estáveis. Já aí se pode ver que é o senhor branco quem destrói as famílias, havendo, por exemplo, um escritório do crime em Nova Iorque, dedicado a sequestrar negros para a lavoura (Greenidge, 2020).

Para assegurar sua continuidade, o escravismo moveu inúmeras batalhas judiciais, afirmando o direito do senhorio de ser proprietário de seres humanos, em toda parte do território e a qualquer momento. A tolerância com que contava e o seu peso para a História da riqueza do homem branco entreabri- 
ram possibilidades à reescravização (ilegal) e ao tráfico (ilegal). Também entrou no jogo das estimativas possíveis a instauração da escravatura nos estados onde o cativeiro não tinha vigor (Baptist, 2019, p. 488). A ilha de Cuba, adicionalmente, figurou nos planos de anexação territorial e demográfica (Baptist, 2019, p. 468), dado o seu alto valor como província açucareira escravocrata. A escravidão, portanto, não recebeu nenhuma sentença apontando para o seu fim. Antes, empenhou-se firmemente em prol de seu futuro, com lucros ardentes e adeptos fervorosos.

Mais ainda, a escravidão não existiu sem o interesse do Norte dos Estados Unidos. "Os senhores dos teares da Nova Inglaterra" - isto é, os burgueses, que replicavam, nos EEUU, a elite industrial têxtil da Inglaterra - recorriam ao "algodão produzido por escravos" e, assim, fizeram as maiores fortunas do Norte (Baptist, 2019, p. 419). Porém, em dado momento, a elite branca de Nova Iorque começou a acreditar - e a fazer crer - que "nunca tinha vendido um fardo de algodão" (Baptist, 2019, p. 436). Cientes dessa hipocrisia, os sábios homens brancos sulistas "não viam o seu próprio sistema como algo antiquado, destinado a ser atropelado pelo futuro". Ao contrário, seus lucros eram a prova da escravidão ser economicamente proveitosa e capaz de longa duração (Baptist, 2019, pp. 445, 447). Nem por isso deixavam de explorar a ideologia abolicionista do Norte, pois assim reclamavam melhores condições políticas e econômicas para o Sul. Por fim, até para quem não possuía escravos, o recurso à escravização dos negros se associava perfeitamente à "liberdade, modernidade e à vida econômica liberal” (Baptist, 2019, p. 477).

Embora não fosse aceita em todos os estados, a escravidão encarnava o esqueleto nacional, implicando sábios homens brancos de ambas as regiões numa ampla engenharia partidária e eleitoral. A consequência direta é considerar o pós-abolição como um período em que o apego à supremacia branca se mantém perceptível com os linchamentos, o encarceramento em massa e a brutalidade policial, assim se obtendo o "trabalho organizado" (expressão senhorial brasileira para denominar o projeto de obrigar proletários livres ao trabalho). Contra os mundos do trabalho e da liberdade, pretensões de supremacias de classe e racial andam de mãos dadas, detendo trabalhadores, restringindo seu direito de ir e vir, tolhendo suas vidas.

Não é por acaso que o neto de africano e filho de fugitivo Charles Ball um bom trabalhador, alguém de confiança para qualquer patrão - é personagem destacada do início do livro. Mesmo investindo boa parte de sua inteligência e seu comportamento nos prestimosos servidos oferecidos por suas boas mãos, Ball foi vendido em 1805 e obrigado a abandonar a família. A transação 
não desfez apenas seus sonhos de trabalho, família e liberdade. Preso à "turma da corrente" (chain gang), Ball foi conduzido coercitivamente de uma tradicional província fumageira para o crescente território do algodão. Seguindo seus passos, Baptist descortina um "mercado" vicejante, onde homens de bem possuíam liberdade de iniciativa, tal qual o proprietário que põe Ball no eito e o faz perceber sua nova realidade - a qual era não exatamente o algodão, mas a subida do algodão na economia global, primeiro como a principal matéria-prima da Revolução Industrial inglesa e, em seguida, como a principal matéria-prima da industrialização têxtil da Nova Inglaterra (região nordeste dos EUA, com destaque para o estado de Massachusetts). Sem contar com a legalidade do tráfico desde 1807, os fidalgos escravocratas do algodão recorreram à inovação comercial e financeira, apostaram no desenvolvimento da imprensa, dos transportes e das comunicações e se fizeram passar por sábios homens brancos, de cujo meio viriam à luz as lideranças as mais dignas e sagazes (Baptist, 2019, p. 468). Era o que diziam.

Sobretudo, racionalizaram a produção algodoeira torturando homens e mulheres catadores de algodão no Alabama, no Mississippi, na Louisiana e no Texas. Ao trazer à tona os lucros e o seu crescimento, o livro supera a imagem de pobreza e atraso do Sul. Somando-se à migração forçada de um milhão de escravizados (inclusive crianças), açoites eram regra e costume para trabalhadores atingirem a meta e, mais importante que isso, para impingirem, pela dor, o continuado melhoramento das "mãos" - no Brasil eram "braços" - em sua destreza de, mais e mais, atingirem, e baterem, as metas de algodão catado. Como se fosse uma conta bancária, "crédito e débito" são os termos sublinhados pelo autor para expor o cálculo das "pesagens e chicotadas" (Baptist, 2019, p. 185). A leitura do livro evidencia que a escravidão aprisionava homens e mulheres negros em lavouras sob intenso regime de tortura, no cotidiano de trabalho (não apenas como medida punitiva). Tolhendo o seu ir e vir, acorrentando e trancafiando (se assim julgado), eram fazendas prisionais. Em paralelo, os ditos "pais fundadores" - sábios homens brancos ao espelho - se esmeraram em longas querelas pelo irrestrito direito de ir e vir do senhor de escravo na companhia de (seus) escravizados, inclusive em estados refratários ao escravismo. Nesse regime de cativeiro, os escravizados conseguiram, apesar de tudo, se erguer em confrontos, revoltas e em fugas, sendo este, aliás, o caso (bem-sucedido) de Charles Ball. Também demonstraram notável inteligência e presença para protagonizar processos judiciais em favor de sua libertação do cativeiro.

Baptist não tem sombra de dúvida sobre a escravidão encorajar a inovação e a produtividade empresariais. Para tal, ele aponta para o apelo ao chicote 
como correia transmissora da energia do braço operário até o cesto repleto de algodão. Torturando trabalhadores negros com frequência diária, a sociedade estadunidense forneceu a matéria-prima das fábricas têxteis, em quantidades crescentes e baratas. É a respeito disso que uma dura controvérsia foi acesa, tendo Oakes (2020) vocalizado expressiva parte das críticas. Para ele, Baptist não só não tem o apoio que afirma ter quanto às fontes: ele é por elas desmentido, em particular quanto ao sistema de cota, que seria o meio pelo qual a lavoura teria produzido mais e mais algodão. Ainda afirma que Baptist não percebe que nem toda plantação era gerida como a racionalidade de uma fábrica de automóveis. Vendo a economia escravista como híbrida, Oakes (2020) admite serem capitalistas os senhores de escravos, mas não reconhece os escravizados como um proletariado capitalista.

Embora as críticas sejam perfurantes, cumpre ponderá-las. Em primeiro lugar, como afirmou Rosenthal (2020, p. 297), a economia sulista era tão "violenta" quanto "dinâmica, aquisitiva e flexível" e, por isso mesmo, nenhum dos críticos de Baptist de fato descartou a ênfase, nem na "intensidade do trabalho", nem na "ameaça de tortura". Em segundo lugar, é bom frisar que o capitalismo não se fixou no padrão fordista de produção industrial em massa, preços módicos e salários pagos a trabalhadores ocupadíssimos; não só com a linha de montagem, mas também com o consumo de produtos vendidos no mercado (ansiosos, ainda mais, por férias remuneradas). É também bom considerar seriamente a provocação de Julius Scott $(2018$, p. 2): trabalhadores “livres” são mais “anomalia" do que "regra". Outro ponto notável está no fato de os escravizados não serem, mesmo, um proletariado industrial (apesar de também terem sido), bem como de não serem a maior parte do proletariado do século XXI (apesar de também serem). Vale ainda observar que a multidão inglesa do século XVIII era “sui generis", escreveu Thompson (1974, pp. 396-398): era dona de “seus próprios objetivos" e atuava "dentro de uma polaridade de forças delicada e complexa, peculiar ao seu próprio contexto”. Da mesma forma, os escravizados são parte da classe trabalhadora estadunidense. Mais do que salários e fábricas, analisar as relações de trabalho permite entender o lugar dos escravizados na História, de modo a reconciliar as narrativas dos séculos XIX e XX.

Perante a prática da tortura, cuidadosamente contabilizada em açoites devidos à falta de algodão catado, o conceito e o fenômeno do paternalismo senhorial quase são abatidos de uma vez por todas. Por meio da crítica à autoimagem senhorial de benevolência, as pesquisas têm se valido do conceito de paternalismo para reconhecer e analisar a relação senhor-escravo. Porém, na lavoura algodoeira, não parece haver espaço algum para o paternalismo. Apesar 
do interesse na reprodução dos escravizados e na catequização religiosa, os proprietários não se dispunham a obrigações recíprocas. "Em todas as etapas do processo, da semente à fábrica, e da fábrica ao consumidor", os detentores do capital "dividiram em fatias as margens de lucro geradas nas costas" - torturadas - "dos afro-americanos escravizados e serviram cada fatia para um ator na economia mundial" (Baptist, 2019, p. 414). O algodão era o bem "essencial" dessa economia de escala planetária e, seguramente, os senhores consideravam não ter tempo para gastar com uma relação de reciprocidade.

Sucede que os escravizados precisavam tirar alguma coisa da relação senhor-escravo, para sua própria sobrevivência, e aí cumpre perceber suas roças até na Louisiana algodoeira; valioso costume em comum em meio ao inferno (o que, para os senhores, era um jeito de economizar nos custos da alimentação). Quando o preço do algodão caía, era menos difícil arrumar tempo e autorização para suas roças de algodão, milho, fumo e hortaliças. Porém, até quando o preço era bom, os trabalhadores dariam o maior duro para não perderem o seu roçado, com o que podiam não só comer melhor, mas também comprar roupas, fumo, bebidas (Baptist, 2019, p. 406). Logicamente, a assimetria das experiências levava à falta de consenso sobre seus resultados. No caso dos negros, fica patente sua capacidade não apenas para o trabalho morigerado, mas também de atuar no mercado.

Mesmo naquelas ocasiões em que os escravizados e as escravizadas não tinham chances de abrir brechas no paternalismo senhorial - nos momentos terríveis, quando eram vendidos em leilões, ou na condição de "sexualização forçada" das escravizadas -, se faz notar a sua presença, o que Baptist diligentemente percebe e analisa (Baptist, 2019, pp. 142-149). Na verdade, tal qual os escravizadores, os escravizados descartavam o paternalismo quando podiam, a exemplo das fugas e revoltas (ainda que, se mal sucedidos, tivessem de reativar seu tirocínio em lidar com os senhores segundo os termos do paternalismo). Também estavam ligados em tudo ao redor. Um senhor, por exemplo, não podia alforriar uma dúzia de escravizados sem o medo do desejo de liberdade da parte dos demais, mantidos em cativeiro, quer na sua propriedade, quer nas vizinhanças. A presença laboriosa dos escravizados aparece até mesmo na substituição desumanizadora do termo senhorial "cabeça" por "mãos", para fazer referência aos negros e às suas "mãos trabalhadoras" (Baptist, 2019, p. 145).

Em vista disso, Baptist bem podia ter contemplado os escravizados, ou trabalhadores, no título de sua obra. De fato, nas 552 páginas do livro, há abundante material para aludir aos escravizados na História da formação do capitalismo, como uma classe operária, diversificada pelas suas incríveis des- 
trezas, habituada a uma gama variada de ofícios urbanos e rurais. Apesar de seu desejo expresso de comprar "mãos” (e não mais “cabeças"), os senhores apreçavam alto o valor dado aos trabalhadores de ofício (Baptist, 2019, p. 149). No título original, a menção a making (traduzida como "construção") não vincula ninguém a E. P. Thompson e ao seu livro The making of the English working class (1963), mas Baptist, com certeza, resgata os escravizados do passado como uma classe social, presentes ao seu próprio fazer-se. Também não se vale de condescendência, pois recorre à compreensão histórica. Como resultado, "os afro-americanos sabiam muito bem o que pensavam a respeito da expansão da escravidão" (Baptist, 2019, p. 257). "Migrantes forçados iletrados" dispunham de sua própria "filosofia" (Baptist, 2019, p. 265). Sendo seres presentes, eram experientes e expertos nas relações sociais vividas. Além de rebeliões e fugas, os escravizados aperfeiçoaram sua cultura política passo a passo, com o revigoramento da escravidão. Podiam figurar no título.

A atração que o autor parece sentir ao descobrir uma nova e poderosa fronteira econômica (o algodão), que deixa para trás a "morte" da "velha escravidão", instruiu seu olhar. Ele indica, então, um "processo moderno e modernizador” (Baptist, 2019, p. 113), o que o embaralha na já criticada dicotomia da morte de um para o progresso de outro, da novidade de um perante a velhice de outro. É nesse trecho do livro (Baptist, 2019, pp. 83, 87) que aparece sua filiação à historiografia da segunda escravidão - avaliada por Izecksohn (2016) -, a qual considera a lavoura do algodão como carro-chefe de um novo mundo, mais amplo e moderno (Baptist, 2019, p. 102). Na medida em que o país entrou em guerra civil, não é para se levar ao pé da letra o falecimento da primeira escravidão, a começar pelo fato de a Virgínia não só ser celeiro de presidentes estadunidenses, como também a capital confederada. Se a escravidão estivesse sepultada nessa região antiga, não haveria escravocratas para defenderem-na.

A ênfase na mercadoria do algodão como o bem global primário do XIX vai impulsionar o interesse dos programas de pós-graduação pela História global. Vai incentivar na juventude esse mesmo interesse. Haverá cada vez mais curiosidade investigativa sobre atividades extrativas, agrícolas ou fabris, e seus vínculos com a economia global. Será, ao mesmo tempo, necessário observar a importância da diferença do pequeno, a exemplo do cultivo de milho, feijão e farinha, junto da criação de animais, como uma estratégia de segurança alimentar. Enquanto os senhores consumiam modas para requintar sua fortuna hedionda, os trabalhadores preservaram sementes crioulas de plantas autóctones. É bom que essa metade também seja computada. Note-se: ela não escapa a Baptist, que retrata as rodas de debulhar milho como um mo- 
mento de tessitura de solidariedades horizontais e virtuosismo artístico (Baptist, 2019, p. 218).

Anticlímax da guerra, o capítulo "braços" condensa a obra em nuvem carregada e precipita uma aguda percepção da História dos Estados Unidos (além de seu gancho com a atualidade). Em primeiro lugar, o livro, a esta altura, já não trata mais da insegurança ou dos ressentimentos do Norte perante as artimanhas e a valentia do Sul. No final da década de 1850, a escravidão não era ineficiente nem se via sem futuro, sendo cogitadas inauditas transações, providenciadas pelo tráfico negreiro, em vigor noutros lugares (Baptist, 2019, p. 495). Nesse ponto da História, a pressão pela expansão (sem freios) da escravidão não tira folga e leva Abraham Lincoln a entender que a União não tinha mais como prosperar - indefinidamente - com uma banda livre e outra escravista (Baptist, 2019, p. 488). Arguto, o lenhador bom de prosa não nutria expectativas do Sul se retrair acabrunhado no canto, após concordar com a impossibilidade do crescimento geográfico da escravidão. Bem ao contrário, o Sul queria liberdade absoluta para espalhar cativeiro por tudo quanto era lugar, inclusive pela banda livre. Clarividente, Lincoln desenhou o dilema: a União "se tornará uma coisa ou outra”. Para o Sul, a escravidão não tinha de acabar. Era o que pensavam, pois presumiam ser isto não apenas o fim do dinheiro, mas de toda uma elegante civilização (chamada de ocidental); um varonil modo de vida. Para não ter de admitir os estupros das mulheres negras, contava-se a mentira da perda da virgindade das mulheres brancas, assaltadas pelos negros. A abolição em todo território, em suma, não passaria em brancas nuvens.

O livro parece ser arauto dos conflitos vigentes nos EEUU. O que Lincoln intuía era o perigo da defesa da escravidão ameaçar a própria viabilidade da América como a terra dos livres. Princípios e instituições que, desde 1776, tinham aberto oportunidades sem precedentes estavam sendo torcidos ao ponto de serem esgarçados para sempre, ameaçados pela confiança dos senhores na prosperidade da escravidão, o que "minava o futuro da liberdade para brancos e negros" (Baptist, 2019, pp. 485, 488). De fato, em seu livro, Harris (2020) detectou a presença, em 1862 (já com o país em plena guerra civil), de navios negreiros atracando e zarpando do porto de Nova Iorque, apesar dos mais de 50 anos do fim do tráfico, ocorrido em 1807. Visivelmente, os interesses do tráfico se mantinham ativos por sobre os lados em conflito, contagiando a vida nacional ao espalharem escravismo. Como Daniel Silva (2020, p. 571) sublinhou, a escravidão não era um barco destroçado e à deriva. Ao invés disso, mostrou capacidade de emigração para novos lugares, incorporando novos tipos de tecnologias industriais. Por sinal, Boyer (1973, p. 468) indicou 
que essa possibilidade existia em 1854. "O governo", escreveu o abolicionista Wendell Phillips, "está inteiramente nas mãos do poder escravista”. Ouvindo rumores em favor das anexações territoriais de Cuba e México aos EEUU, ele receava a volta do tráfico negreiro. Ele também temia a entronação de um "vasto império escravista unido ao Brasil".

Atualmente, enquanto as pretensões de supremacia racial não aceitarem distribuição de renda em benefício direto da população afrodescendente, a classe trabalhadora permanecerá marginalizada do bem-estar social que a economia produz. Enquanto houver racismo estrutural e o mercado se expandir sem limites, chegando a todo lugar e tudo comprando e vendendo, a nação se tornará uma coisa ou outra: ou mercado, ou democracia.

Quanto mais vemos em xeque as conquistas contemporâneas do bem-estar social, mais parecem andar em alta os planos dos senhores de escravos para o pós-abolição: seu modo de ver o mundo - liberal na economia, excludente na política, patriarcal na família, racista no cotidiano, apoiado por milícias e polícias - teve influência maior do que sua própria atuação em vida. A ideia de contratadores alugarem a força de trabalho sem terem de alimentar vínculos ou observar direitos, dispensando a mão-de-obra arbitrariamente, tornando os empresários irresponsáveis pelo que sucede à classe operária, anima um sistema desenhado para faltar ao empregado toda vez que este carecer de amparo, proteção ou socorro (isto para não se falar do assalariamento). Enquanto essa ideia estrutura plataformas tecnológicas ou se evidencia na terceirização, não só os direitos estão ameaçados de morte, como os trabalhadores estão sujeitos à indignidade.

O erro de se pensar numa transição está, em resumo, no fato de não se perceber que a escravidão é um fenômeno empenhado no sentido de sua continuidade e expansão, sem data para acabar. Do ponto de vista patronal, a transição jamais existiu e sempre foi uma dramática travessia, que, na ficção, poderia ser televisada em roteiro ainda por ser escrito, Vivendas das pedras. Sair da margem da escravidão e atravessar o rio escolhendo pedras sólidas para a propriedade privada (garimpando a vida alheia). Chegar à outra margem, contrária à liberdade e à cidadania dos negros e da classe operária. Nesta outra margem, o senhor branco vai se professar receoso em seu condomínio ou latifúndio, carente de armas para impor sua masculinidade e comando. Vai erguer muros e se cercar de vigilância, enquanto quer ver a economia funcionando com braços e mãos de homens e mulheres livres, mas obrigados ao trabalho.

Livros como esse de Baptist são grandes até para quem lê com hábito e gosto. Exigem investimento de informação, disposição e persistência. A leitu- 
ra de $A$ metade que nunca foi contada é, de todo modo, recompensada, já que os tópicos, nos capítulos, têm a energia da contagiante inteligência do autor, para encanto de quem gosta de História. Felizmente, o empenho de vê-lo traduzido e impresso em português deu super certo, e aí está.

\section{REFERENNCIAS}

BAPTIST, Edward. A metade que nunca foi contada: a escravidão e a construção do capitalismo norte-americano. Rio de Janeiro: Paz \& Terra, 2019.

BOYER, Richard O. The Legend of John Brown: a Biography and a History. New York: Knopf, 1973.

GREENIDGE, Kerri. Enslaved, Terrorized, Disenfranchised: Black Americans Still Found Ways to Change America [South to Freedom. Runaway Slaves to Mexico and the Road to the Civil War. By Alice L. Baumgartner; The Kidnapping Club. Wall Street, Slavery, and Resistance on the Eve of the Civil War. By Jonathan Daniel Wells]. 16 nov. 2020. Disponível em: https://www.nytimes.com/2020/11/16/books/ review/south-to-freedom-alice-baumgartner-the-kidnapping-club-jonathan-daniel-wells.html?smid=tw-share. Acesso em: 20 nov. 2020.

HARRIS, John. The Last Slave Ships: New York and the End of the Middle Passage. New Haven: Yale University Press, 2020.

IZECKSOHN, Vitor. Os desafios da segunda escravidão. Afro-Ásia, n. 54, pp. 345-353, 2016.

OAKES, James. A Few Random Thoughts on Capitalism and Slavery. 21 set. 2020. Disponível em: https://economic-historian.com/2020/09/a-few-random-thoughts-on-capitalism-and-slavery/. Acesso em: 20 nov. 2020.

ROSENTHAL, Caitlin. Capitalism when Labor Was Capital: Slavery, Power, and Price in Antebellum America. Capitalism: A Journal of History and Economics, v. 1, n.

2, pp. 296-337, 2020.

SCOTT, Julius. The Common Wind. Afro-American Currents in the Age of the Haitian Revolution. Londres: Verso, 2018.

SILVA, Daniel B. Domingues. The Reinvention of Atlantic Slavery. Technology, Labor, Race, and Capitalism in the Greater Caribbean. Hispanic American Historical Review, v. 100, n. 3, pp. 571-573, 2020.

THOMPSON, Edward. The Making of the English working class. London: Gollancz, 1963.

THOMPSON, Edward. Patrician Society, Plebeian Culture. Journal of Social History, Oxford University Press, v. 7, n. 4, pp. 382-405, 1974.

Resenha submetida em 21 de novembro de 2020.

Aprovada em 21 de dezembro de 2020. 